\title{
Utilizing Ultrasonic Waves in the Investigation of Contact Stresses, Areas, and Embedment of Spheres in Manufactured Materials Replicating Proppants and Brittle Rocks
}

\author{
Kamel Fahmi Bou-Hamdan ${ }^{1,2}$ (D) Azza Hashim Abbas ${ }^{3}$
}

Received: 9 August 2021 / Accepted: 11 November 2021 / Published online: 2 December 2021

(c) The Author(s) 2021

\begin{abstract}
In the oil and gas industry, hydraulic fracturing (HF) is a common application to create additional permeability in unconventional reservoirs. Using proppant in HF requires understanding the interactions with rocks such as shale, and the mechanical aspects of their contacts. However, these studies are limited in literature and inconclusive. Therefore, the current research aims to apply a novel method, mainly ultrasound, to investigate the proppant embedment phenomena for different rocks. The study used proppant materials that are susceptible to fractures (glass) and others that are hard and do not break (steel). Additionally, the materials used to represent brittle shale rocks (polycarbonate and phenolic) were based on the ratio of elastic modulus to yield strength $(E / Y)$. A combination of experimental and numerical modeling was used to investigate the contact stresses, deformation, and vertical displacement. The results showed that the relation between the stresses and ultrasound reflection coefficient follows a power-law equation, which validated the method application. From the experiments, plastic deformation was encountered in phenolic surfaces despite the corresponding contacted material. Also, the phenolic stresses showed a difference compared to polycarbonate for both high and low loads, which is explained by the high attenuation coefficient of phenolic that limited the quality of the reflected signal. The extent of vertical displacements surrounding the contact zone was greater for the polycarbonate materials due to the lower $E / Y$, while the phenolic material was limited to smaller areas not exceeding $50 \%$ of polycarbonate for all tested load conditions. Therefore, the study confirms that part of the contact energy in phenolic material was dissipated in the plastic deformation, indicating greater proppant embedment, and leading to a loss in fracture conductivity for rocks of higher $E / Y$.
\end{abstract}

Keywords Hydraulic fracture - Contact stresses · Phenolic · Polycarbonate · Proppant embedment · Unconventional reservoirs · Ultrasonic waves · Vertical displacement, Spheres

\section{Abbreviations}

$D \quad$ Transducer element diameter [mm]

E Young's modulus [MPa]

$R \quad$ Reflection coefficient

$R_{\text {critical }}$ Critical reflection coefficient located at the contact boundary

\section{Kamel Fahmi Bou-Hamdan}

kamelbh@live.com

1 Chemical \& Petroleum Engineering Department, Beirut Arab University, Debbieh, Lebanon

2 School of Engineering, University of Aberdeen, Aberdeen, UK

3 School of Mining and Geosciences, Nazarbayev University, Nur-Sultan, Kazakhstan
Yield strength [MPa]

Acoustic impedance $\left[\mathrm{Kg} \mathrm{m}^{-2} \mathrm{~s}^{-1}\right]$

The first parameter in the power-law relation

The second parameter in the power-law relation

Speed of sound [ $\mathrm{m} \mathrm{s}^{-1}$ ]

Focal spot diameter [mm]

Wave frequency [MHz]

A limiting parameter in the power-law relation

Focal length [mm]

A converging factor in the power-law relation

$\sigma \quad$ Stress coefficient [MPa]

$\sigma_{\text {Exp }}$ Mean contact stress measured experimentally [MPa]

$\sigma_{\mathrm{Hz}} \quad$ Mean contact stress calculated using Hertz Law [MPa] 
$\sigma_{\text {Ref }} \quad$ Mean contact stress measured using reflection coefficient $[\mathrm{MPa}]$

\section{Introduction}

Applying forces on any solid surface cause changes in the surface shape. These variations differ based on different material properties such as elastic modulus and yield strength. Most of the solids behave elastically if the forces applied to them are small; when the forces are greater than a certain limit, a large deformation occurs, and this can also cause fractures. Therefore, exploring the stresses and deflections of solids is crucial. The understanding of the deformation can be beneficial for different applications. In the oil and gas industry, hydraulic fracturing (HF) is an application mostly used to create and maintain a fracture in the rock for unconventional reservoirs [1]. HF allows a pathway for fluids to move from the low permeability matrix toward the wellbore. To create effective fractures, the formation is pumped with substantial amounts of proppants to keep it conductive during production. Proppant is an important component of the process because it provides the structural support for the fractures to be created and keeps them open [2].

In unconventional reservoirs, the proppant is injected into the shale formation. This process is considerably complicated. The complications arose because proppant exhibits significant interaction with shale and may alter its shape or deform its surface, which creates asperities that are not counted usually. The full understanding of the proppant contact with the formation depends on the sphere/flat contact deformation. The proppant has a spherical surface, while the rock is considered a flat surface. Reviewing the research on these issues revealed that the impact of different parameters such as proppant size, arrangement and distribution on permeability was studied with conventional conductivity tests. It was proposed that the contact zones deformation between proppant and rocks could be made by measuring the embedment size [3, 4]. This was usually conducted using a surface profilometer or microscopes to view the contact size and embedment after unloading. However, a lot of critical details remain unobtainable such as the distribution of contact stresses on the proppants and the elastic displacements of the fracture face while loading. These parameters are critical and can significantly impact the HF design.

Considering the proppant and shale surface natures made it more significant to revisit the interaction of surface/flat surfaces. The most influential theory is the Hertz theory in 1882 , assuming that the deformation is elastic and the surfaces in contact are smooth [5]. Hertz theory proposed that the radius of the circle contact is proportionally related to the load $(P)$ and the radius $R$. However, it is inverse proportional to the materials' elastic properties. Despite the adequate approach used by Hertz, it did not account for the surface roughness. Since the Hertz theory, several models have been developed to consider the roughness effect. Among these models: Greenwood and Williamson in the 60 's with their statistical approach (GW model) for random hemispherical asperities, BGT model's for elliptical shape, MR and BYC models for plastic deformation of asperities upon contact and KYH, JS and LET considered both elastic and plastic deformations of asperities [6-10]. All the models had found that roughness can show a larger nominal contact area than smooth surfaces at low loads. However, the impact of asperities roughness becomes negligible at higher loads where the bulk deformation becomes dominant. Generally, the asperities deformation and the interaction between spherical and flat surfaces were extensively studied for different applications, yet their designated interaction for oil and gas application is limited. These models cannot provide accurate results in the proppant-rock interaction as they cannot account for a lot of uncertainties such as different proppant sorting. Therefore, the industry still lacks new advanced measuring methods that can be used to find both the distribution of stresses and the resulting proppant embedment.

Many methods were used to measure the deformations including, but not limited to, surface profilometer and microscopes. Although these methods are widely used, they are limited to applications where the measured surface is directly facing the testing equipment. Hence, the contact of spheres and plates can only be assessed after unloading. This means that all the elastic deformations during loading will not be accounted for using these measurement methods. Simple analytical and numerical models can be used to account for the elastic and plastic stresses combined. To better represent the contact conditions experimentally, a pressure-sensitive film can be placed in between the two bodies in contact. These films hold micro-encapsulated dye which breaks down upon reaching its rated compressive strength. Any change in the colors of the film indicates the occurrence of deformation in the contacted surfaces. However, some debate around the role of the films in modifying the contact surfaces has arisen. It is thought that placing those films in between the two contacting bodies modifies the initial contact conditions and hence was shown to overestimate the contact size [11]. Therefore, using the non-destructive testing (NDT) methods were endorsed to avoid controversy, since the measurements can be obtained during contact without damaging the tested samples. One of the NDT methods is the ultrasonic waves that were used in various engineering applications [12-16]. The advantage of ultrasonic waves is that it gives access to the contact interface without modifying the real contact conditions. In addition to that, ultrasound waves can reach locations that may not be accessible to the observer. The track of applying ultrasound waves advanced in different aspects such as measuring the interfacial stiffness of two aluminum blocks [17], measur- 
ing the nominal contact shape and size of wheel-rail contact [18], assessing the contact parameters of sphere-plate contacts [11], monitoring the local dynamics of friction joints [19], and dynamically measuring the contact using arrays of transducers [20].

Although ultrasound usage is growing, expanding the application's aspects is necessary, especially for different material and shapes deformation. This can be fruitful in studying the proppant/shale interaction during HF. Thus, the current research aims to apply the ultrasonic method in testing HF-related deformation, more specifically, the proppant embedment phenomena in different rocks under different loads. However, few issues arise in attempting to use ultrasonic waves directly in rocks such as shale, due to the heterogeneous nature of these rocks. This heterogeneity would disrupt the passage of ultrasonic waves inside the rock and hence cause a lot of scattering that will prohibit obtaining any useful data. Another limitation is that the ultrasonic technique which is used in measuring the contact size and stresses is sensitive to the actual size of the contact, and hence small contact sizes will not produce accurate results. For these reasons, the heterogeneous rocks and the smallsized proppants were replaced with other materials that are of comparable mechanical properties. Moreover, the experimental study tests for different proppant materials such as those susceptible to crushing and others that are hard and do not break. The study has a comparative angle to the role of the expected deformation on contact size, stress distribution, and deformation behavior for the inner and outer contact region. All these parameters are related to proppant embedment, proppant crushing, and fracture conductivity. The research potentiality serves the endeavors of an efficient and cheap alternative to study the physics and contact theories regarding the interaction of proppants and rocks instead of using simple analytical or numerical solutions. Unlike other experimental studies, it considers all the deformations that take place during loading (reservoir drawdown), including both the elastic and plastic deformations. Apart from being utilized in studying the interaction of proppants and shale in $\mathrm{HF}$, this study is also relevant in other applications focused on contact mechanics. This study is the first to examine the applicability of the ultrasonic measurement technique on small contact sizes and the contact between dissimilar materials.

\section{Methodology}

In this study, a combination of methods was adopted. The methodology includes an experimental study and numerical modeling. The approach used allows deep investigation of mechanical properties' effect on the deformation behavior at increasing loads. The new framework accommodates the possibility to represent different reservoir rock types because it allows the selection of representative material types.

\subsection{Experimental Work}

\subsubsection{Apparatus}

The cell prototype is made up of polycarbonate material and can be divided into three main parts numbered. The top part serves as a water tank and has a hole in the middle that acts as a scanning window. The middle part acts as a wall that can seal all fluids or solids inside the cell. The bottom part is mobile and can slide between the middle part's walls as the load is applied. The main cell is connected to a loading instrument from its bottom part, where a digital transducer is used for measuring the applied load. A thin plate material can be fixed between the top and middle parts. The apparatus setup is depicted in Fig. 1.

Ideally, the shape of the proppant should be spherical to maximize the HF capability. Therefore, spherical objects were used in this study. Two different spheres that are made up of glass and steel were selected. Both materials are suitable in this study as they are analogue to proppant in the fractured reservoir. It is essential to state that the proppant deformation is always very small, almost negligible compared to that of the rock, such as shales. This is mainly due to the significant difference in rocks' and proppants' Young's modulus where the latter can be over ten times larger. The same condition is satisfied in this experiment where the Young's modulus of glass (70 GPa) and steel spheres (200 GPa) are over ten times larger than the tested materials shown in Table 1. So, the spheres selected in this experiment were treated as rigid bodies that undergo minimal deformations.

As mentioned previously, actual shale rocks cannot be directly used in this kind of experiment due to several reasons including the heterogeneity nature of these rocks. Therefore, the brittle shale rocks should be replaced with other useable materials that can show a similar deformation behavior under loading conditions. It is common to use the ratio of elastic modulus to yield strength $(E / Y)$ in indentation experiments as means of comparing the susceptibility of the materials to deformations [21, 22]. As this ratio decreases, the material tends to show a brittle deformation behavior, and as the ratio increases, the material tends to show plastic deformation behavior. Therefore, both polycarbonate and phenolic plates were selected in this experiment since the ratio $(E / Y)$ of these materials, shown in Table 1, is comparable to the brittle shale rocks that are shown in Table 2. It should be noted that the exact value for strain displacements in the plates will not be equivalent to the shale rocks since their Young's modulus is different. But since they have a similar $E / Y$ ratio, the deformation profile will be the same. 
Fig. 1 a Schematic representation of the experimental setup b Prototype

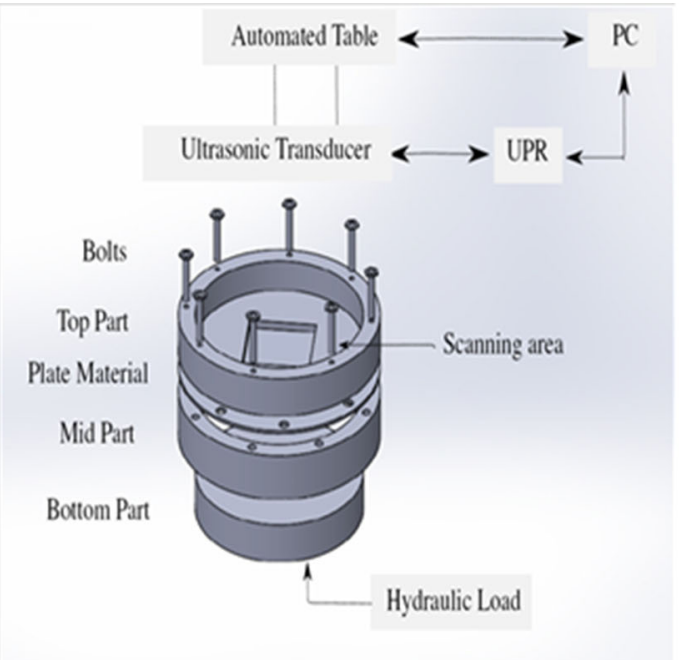

(a)

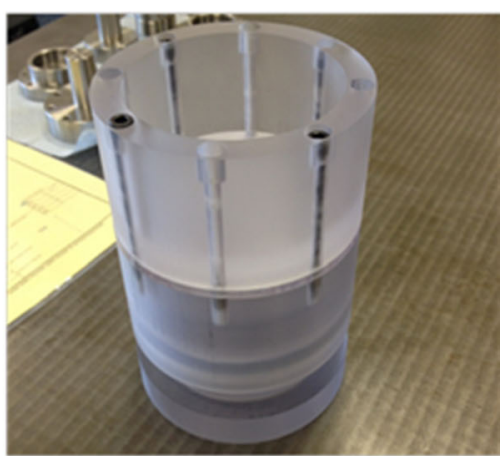

(b)
Table 1 Plate material properties

\begin{tabular}{lllll}
\hline Material & $\begin{array}{l}\text { Young's modulus } E \\
(\mathrm{MPa})\end{array}$ & Yield strength $Y(\mathrm{MPa})$ & $E / Y$ & $\begin{array}{l}\text { Acoustic impedance } \\
\left(\mathrm{Kg} \mathrm{m}^{-2} \mathrm{~s}^{-1}\right)\end{array}$ \\
\hline Polycarbonate & 3000 & 60 & 50 & $2,880,000$ \\
Phenolics & 4800 & 48 & 100 & $3,862,400$ \\
\hline
\end{tabular}

Table 2 Mechanical properties of some brittle shale gas reservoirs in the United States [23]

\begin{tabular}{llll}
\hline Shale rocks & $\begin{array}{l}\text { Young's modulus }(E) \\
(\mathrm{MPa})\end{array}$ & $\begin{array}{l}\text { Yield strength }(Y) \\
(\mathrm{MPa})\end{array}$ & $E / Y$ \\
\hline Barnett Shale & 46,000 & 300 & 153 \\
Shale 2 & 53,400 & 517 & 103 \\
Shale 3 & 13,000 & 100 & 130 \\
Shale 4 & 21,500 & 170 & 126 \\
\hline
\end{tabular}

A $10 \mathrm{MHz}$ focused ultrasonic transducer manufactured by Olympus was attached to an automated table to make measurements at distinct locations. The table can adjust the location of the transducer in both $\mathrm{x}$ and $\mathrm{y}$ directions. Manual placement in the z-direction is required to focus the transducer. The table is mounted on a larger fixed frame, as shown in Fig. 2. A USB cable is used to connect the automated table's driving circuit to a PC, which ultimately controls the movement. Additional details regarding the operation of this scanner were previously described in other publications [24, 25].

A small metallic frame was used to hold the polycarbonate cell in place while loading is applied and can be seen in Fig. 2. The upper part of the polycarbonate cell is filled with a connecting fluid (Water) to provide a pathway for ultrasonic waves to access deeper parts of the cell.

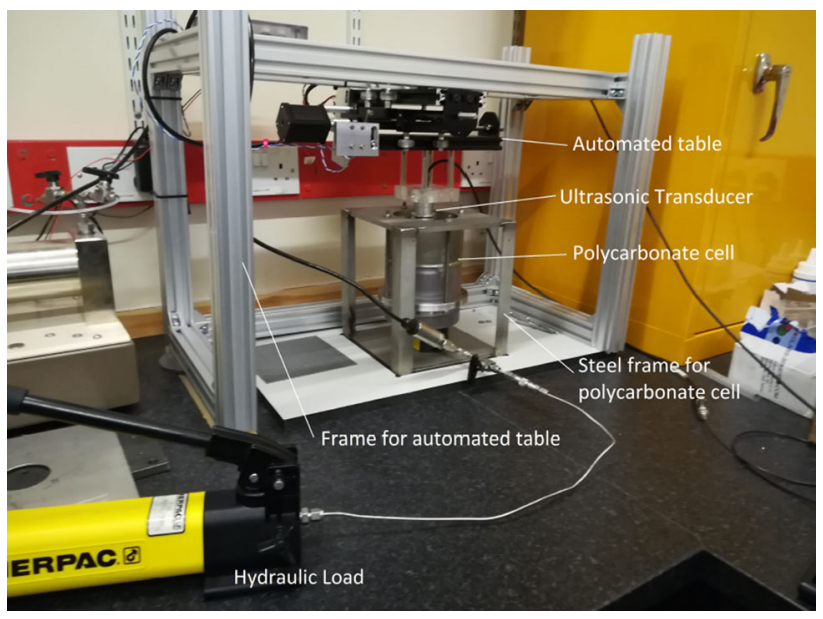

Fig. 2 Assembled Set-up

\subsubsection{Calibration Test}

The calibration test aims to obtain a relationship between the ultrasonic reflection coefficient and stresses. The relationship is critical to understand the material behaviors and it is not readily available.

The plate was placed as a sandwich-like configuration between the top and middle part of the polycarbonate cell. A cylindrical object of $5 \mathrm{~mm}$ outer surface diameter is used as the second test specimen. The specimen has a fixed contact 
area at any applied load [26-29]. This can be used to acquire the mean pressure at any load employed.

$$
\text { Mean Pressure }=\frac{\text { Load }}{\text { Area Fixed Contact }}
$$

The procedure included applying several loads, followed by scanning the material's contact location. The scanning procedure obtains numerous reflection coefficient data for every location and stores them in a matrix form. Both the mean reflection coefficient and the mean contact pressure were compared. The comparison allows the construction of a fitting curve that represents the relation between stresses and the reflection coefficient. It is worth noting that the fitting curve usage is limited to the tested materials e.g., polycarbonate plate and steel objects, so it cannot be used for other materials.

\subsection{Measurement}

\subsubsection{Contact Area}

To measure the contact between sphere and plate, the same procedure employed in calibration tests was used. The only difference is instead of cylinders, the test was using spheres. The reflection coefficient data points at every location along the scanned area were saved in a matrix form, then plotted as an image with contour lines. The procedure was repeated at different loads to observe the changes. The method allowed the observation of any reflection coefficient changes to estimate the contact size, which implies that the contact boundary is reached. It is worth stating that the reflection coefficient is identified by contours separation or by the wave phase shift. This procedure has been used with reasonable accuracy by [29].

\subsubsection{Contact Stress}

Since only a few studies focused on the distribution of contact stresses in proppant and rock interaction, the current method has been used to highlight these stresses. The distribution of the contact stress can be determined from the measured reflection coefficients. The readings were compared to the best fit stress-reflection curve obtained through calibration. Additionally, to allow a comparative view, another set of stress reading was used to validate the results.

\subsection{Numerical Model}

A numerical model that uses the finite element method was assembled using a commercial software (Abaqus). The new model is used to mimic the experimental study and aid in analyzing and interpreting the results. Therefore, similar con- ditions were used in the numerical model to provide the resemblance of the acquired data. In the numerical model, the cylinder and sphere were modeled as rigid bodies.

In all the simulations, a single rigid body was selected to be in contact with a deformable plate. The rigid body sat on top of the deformable plate and was located at its center. The rigid body is then subjected to compressive load in the vertical direction toward the deformable part. Since the boundary conditions of the deformable part prevent it from moving in space, the contacting surface will show signs of deformation. The load was applied on the top of this cylinder and toward the deformable plate, at loads up to $500 \mathrm{~N}$. Since the cylinder is a rigid body, a point load will behave like a uniform load. Table 3 summarizes the different scenarios considered in the numerical simulations.

The main output of the numerical simulation is the estimated vertical displacements, both for the inner and outer contact boundary. Each vertical displacement value obtained from the simulation of rigid cylinders in contact with the deformable plate was correlated to its reflection coefficient at the exact location from the experimental step. Lastly, the relation between the vertical displacement and the reflection coefficient was examined to identify the governing equation. This was later used to confirm the accuracy of using this relation to estimate the vertical displacements at the outer boundaries of the contact. The workflow of this experiment is summarized in Fig. 3.

\section{Results and Discussion}

\subsection{Calibration Tests}

The calibration tests were conducted on cylindrical objects as discussed in Sect. 2.1.2. The contact of those cylinders with the different plate materials was analyzed. The contact boundary between cylinders and the plate materials is easy to locate as the expected contact diameter in the scanned images is equivalent to the surface diameter of the used cylinder. The reflection coefficient at the contact boundary was obtained for different contact problems to ease measuring the mean reflection coefficient inside the contact zone. This can then be compared with the mean contact stress to obtain the relation between stress and reflection coefficient.

The contact boundary between the spheres and the plate materials is more complicated to locate since this boundary is load dependent. Therefore, it is crucial to have a particular reference that can be used to distinguish the contact zone from the non-contact zone. Hence, the critical reflection coefficient ( $\left.R_{\text {critical }}\right)$ of the contact's boundaries was obtained for each experiment independently. The critical reflection coefficient was found to be 0.62 for the contact of phenolic/glass, 0.85 
Table 3 Numerical simulations

\begin{tabular}{llllll}
\hline Simulation & Max load $N$ & Rigid body & $\begin{array}{l}\text { Deformable } \\
\text { plate }\end{array}$ & $\begin{array}{l}\text { Elastic modulus } \\
\text { MPa }\end{array}$ & Yield stress MPa \\
\hline 1 & 500 & $\begin{array}{c}4.7 \text { mm Steel } \\
\text { Cylinder }\end{array}$ & Polycarbonate & 3000 & 60 \\
2 & 500 & $\begin{array}{c}4.7 \text { mm Steel } \\
\text { Cylinder }\end{array}$ & Phenolic & 4800 & 48 \\
3 & 500 & $\begin{array}{r}5 \text { mm Glass } \\
\text { Cylinder }\end{array}$ & Polycarbonate & 3000 & 60 \\
4 & 500 & $\begin{array}{r}5 \text { mm Glass } \\
\text { Cylinder }\end{array}$ & Phenolic & 4800 & 48 \\
5 & 400 & 20 mm Sphere & Polycarbonate & 3000 & 60 \\
6 & 400 & 20 mm Sphere & Phenolic & 4800 & 48 \\
\hline
\end{tabular}

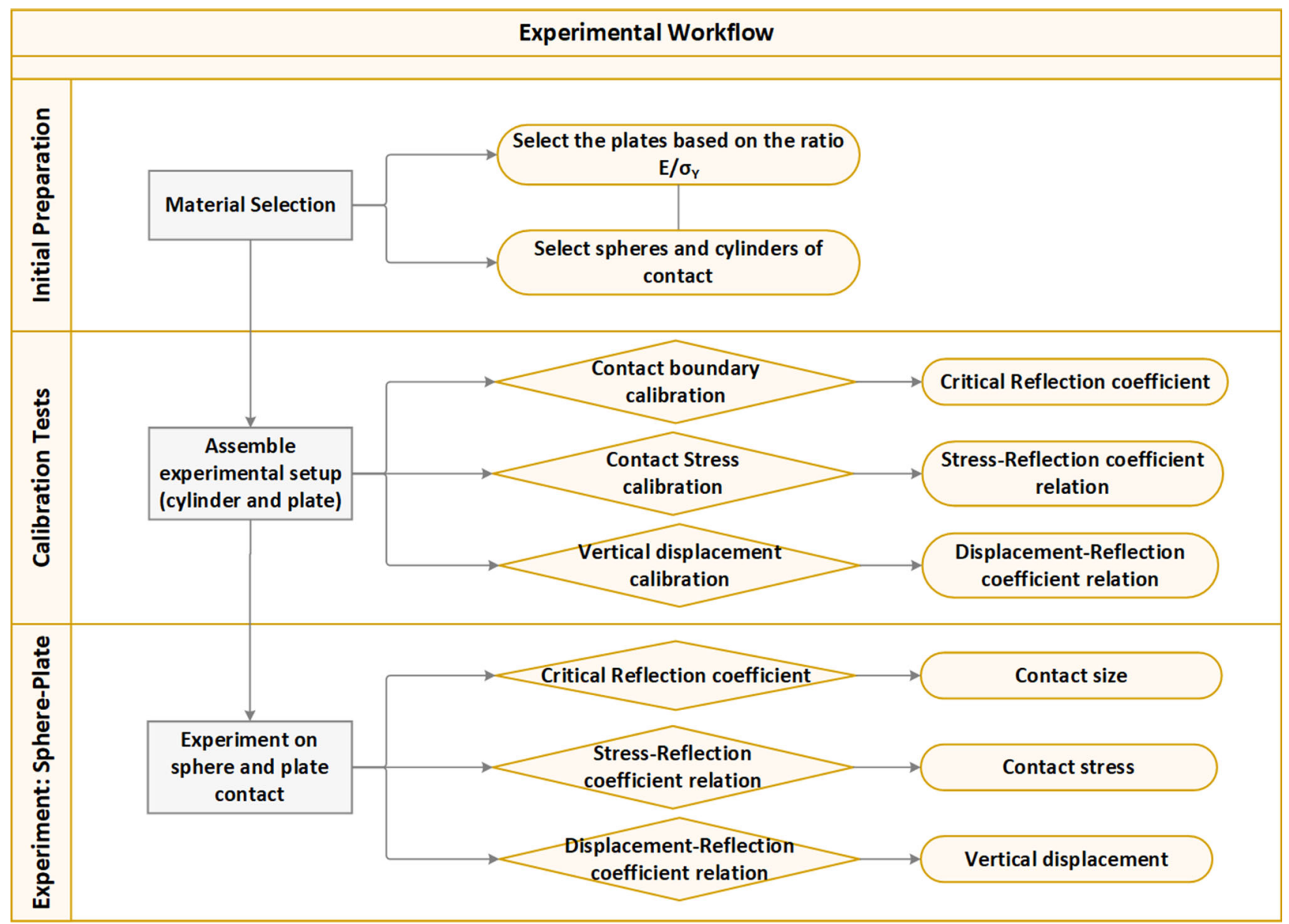

Fig. 3 Experiment Workflow

for phenolic/steel, 0.55 for polycarbonate/glass, and 0.54 for polycarbonate/steel.

Surprisingly, the reflection coefficient outside the contact region in all calibration tests showed a value less than 1 . This finding is controversial to the previous findings, and it suggests that some displacements/stresses are occurring in this region. The high critical reflection coefficient for the contact of phenolic and steel is due to the acoustic properties of the two materials. If a perfect contact is achieved, the reflection coefficient will show a high value. It is possible to calculate the reflection coefficient using Eq. 2 [30].

$R=\frac{Z_{2}-Z_{1}}{Z_{2}+Z_{1}}$ 


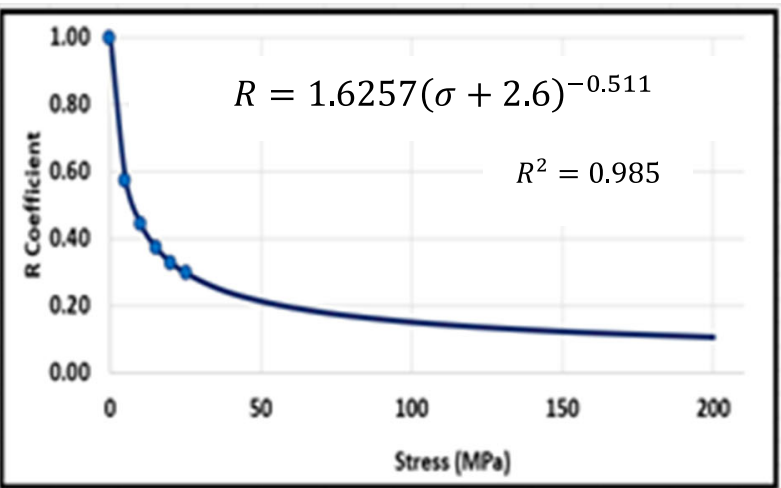

(a) Phenolic/Glass

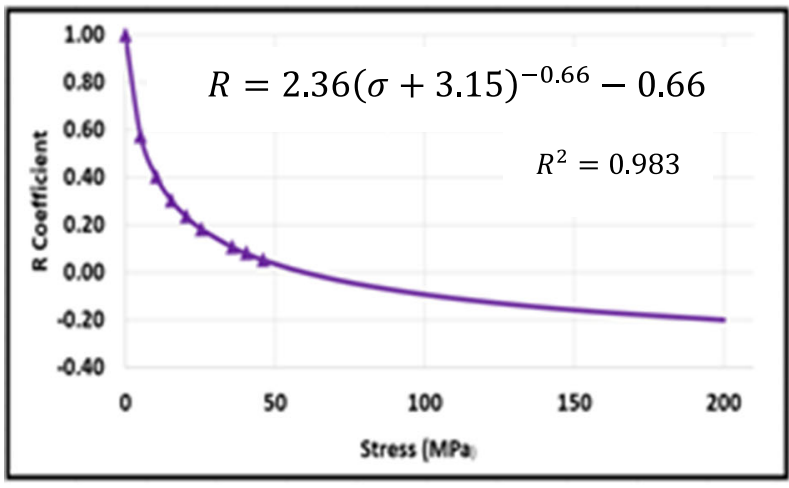

(c) Polycarbonate/Glass

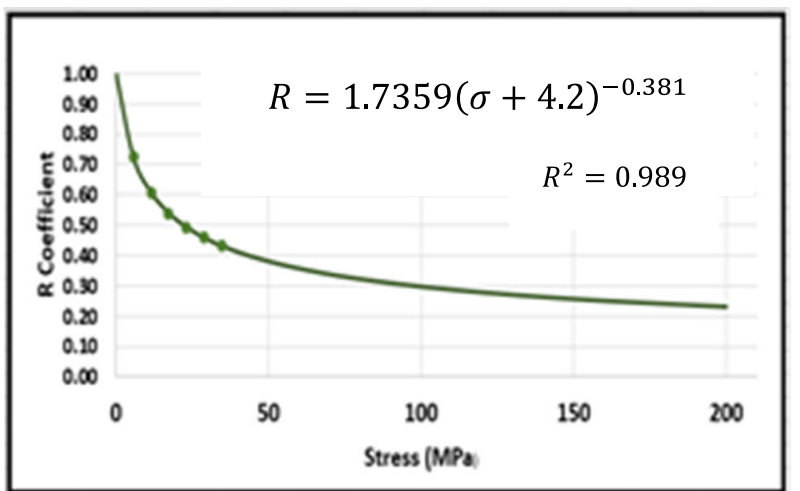

(b) Phenolic/Steel

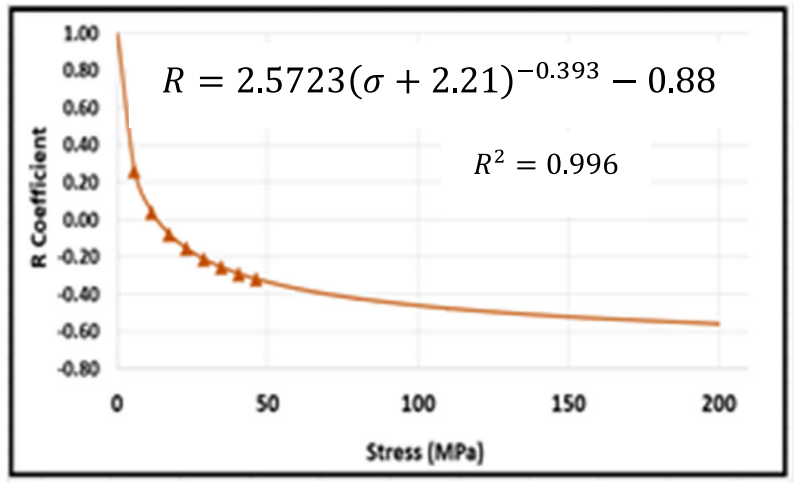

(d) Polycarbonate/Steel

Fig. 4 The relation between stress and reflection coefficient for different contact interfaces: a Phenolic-Glass, b Phenolic-Steel, c PolycarbonateGlass, d Polycarbonate-steel

where $R$ is the reflection coefficient (ratio of the reflected to incident energy), $Z_{1}$ and $Z_{2}$ are the acoustic impedance of the first and second material in contact.

The calibration test results show several relations between the stresses and reflection coefficients for plate and cylinders' contact. A best-fit line through the experimental data was generated using a power-law trend for both polycarbonate and phenolic as shown in Fig. 4. Using a power-law trend allows to control and limit the reflection coefficient values at higher stresses. Similar relations were obtained in previous studies [27]. In this study, the minimum allowed reflection coefficient for a polycarbonate contact is -1 and for a phenolic contact is 0 . These limits were set based on consideration of phase shifts during measurements. The phase shift occurs because waves can propagate in glass and steel at a higher speed than in polycarbonate. Furthermore, a critical value for the reflection coefficient is identified for every contact, which is based on the properties of its acoustic impedance. Based on Eq. 2, the reflection coefficient of a perfect contact between polycarbonate-steel cannot drop below -0.88 value. Similarly, the reflection coefficient for perfect contact between polycarbonate-glass, phenolic-steel, and phenolic-glass cannot exceed the limits of $-0.66,-0.85$, and
-0.57 , respectively. To make use of the material properties, a general power-law relation was used:

$R=a(\sigma+\epsilon)^{b}+k$

where $a$ and $b$ are the main parameters of a power-law equation. $k$ is a limiting parameter that is material dependent. The reflection coefficient approached this value at higher stresses (perfect contact). This occurs since $b$ is of a negative value and hence the first part of the relation tends to zero at higher stresses. $\epsilon$ is a converging factor used to ensure the reflection coefficient equals 1 when no stress is applied $(\sigma=0)$.

\subsection{Contact Area Determination in Spheres}

The spheres were assumed as rigid bodies when calculating the diameter using Hertz law. The experimental measurements for contact diameter are presented in Table 4. It is noticeable that both spheres contact diameters are slightly larger than what has been obtained from Hertz calculation for most of the tested loads. These results were expected since Hertz theory assumes only perfect elastic deformations for smooth surfaces and neglects any plastic deformation. Additionally, the comparison of the determined results indicates 
Table 4 Diameter obtained from the contact of plates

\begin{tabular}{|c|c|c|c|c|c|c|}
\hline \multirow[t]{3}{*}{ Load $(N)$} & \multicolumn{6}{|c|}{ Contact Diameter (mm) } \\
\hline & \multicolumn{3}{|c|}{ Polycarbonate } & \multicolumn{3}{|l|}{ Phenolic } \\
\hline & Steel Sphere & Glass Sphere & Hertz & Steel Sphere & Glass Sphere & Hertz \\
\hline 100 & 1 & 1.3 & 1.25 & 0.7 & 1.1 & 1.07 \\
\hline 200 & 1.5 & 1.7 & 1.6 & 1.5 & 1.2 & 1.35 \\
\hline 300 & 1.9 & 2.1 & 1.8 & 1.8 & 1.3 & 1.55 \\
\hline 400 & 2.2 & 2.4 & 2 & 2 & 1.6 & 1.7 \\
\hline
\end{tabular}

that the glass sphere has greater roughness than the steel. The glass roughness also contributes to increasing contact diameter as shown in the contact with polycarbonate. The same result was not realized when in contact with phenolic material as the contact diameter always appear to be smaller than the steel spheres. It was noted that some cracks were observed on the surface of the glass sphere after loading which could explain the small contact diameter in phenolic.

Applying Hertz elastic theory to phenolic and polycarbonate plates showed considerable contact diameter difference due to the difference in Young's modulus between the materials. Based on Hertz, the contact diameter of phenolic is always lower than that of polycarbonate. Interestingly, the experimental results showed inconsistency between the tested plates. The contact diameter in phenolic material using steel spheres was around $0.3 \mathrm{~mm}$ lower than that of polycarbonate at $100 \mathrm{~N}$ load but approached that of polycarbonate at $200 \mathrm{~N}$, despite the difference in their elastic modulus. This could be interpreted by the plastic deformation that took place at the phenolic surfaces. Moreover, by considering the ratio of elastic modulus to yield strength for both materials, the polycarbonate is two times lower than phenolic. The polycarbonate has a ratio of 50, which is less than 100 for phenolic. In general, the larger this ratio means more plastic behavior is to be expected, which agrees with the interpretation of the proposed results.

\subsection{Contact Stress Determination}

Two experimental methods were used to find the contact stresses. The first method used the reflection coefficient data to give $\sigma_{\mathrm{REF}}$ and the second technique used the nominal contact area to find $\sigma_{\text {Exp. }}$. Both estimated stresses were compared to Hertz stress $\sigma_{\mathrm{Hz}}$. The results are presented in Table 5 .

Quantitatively the difference in the polycarbonate stresses for steel spheres and their corresponding Hertz are insignificant. The measurement of contact stresses for polycarbonate and glass sphere using reflection coefficient showed some variations when compared to the other experimental method. This could be due to some inaccuracy in obtaining the stress-strain relation between polycarbonate and Glass. This inaccuracy is due to some irregularities on the surface of the glass cylinder [31]. Despite this problem, the difference between both experimentally measured stresses becomes insignificant with loading.

Controversially phenolic stresses difference is obviously substantial even at low loads e.g., $100 \mathrm{~N}$. The experimental results of phenolic stresses have wide variations. They appear to be much lower than that calculated from the contact area and Hertz law. This is because the reflection coefficient did not show significant changes under the tested load conditions. The plausible reason for the observation is related to the high attenuation coefficient of phenolic, limiting the amount and quality of the obtained reflected signals. During a Fast Fourier Transform (FFT) analysis for the reflected signal, the $10 \mathrm{MHz}$ frequency did not appear. Instead, most of the signals were composed of low frequencies less than $5 \mathrm{MHz}$. The frequency explains the major effect on the transducer's focal spot diameter which increases with lower frequency resulting in lower resolution. The following relation is used to calculate the spot diameter, and it shows the inverse proportionality with frequency as seen in Eq. 4 [30].

$d=\frac{1.028 c l}{1000 f D}$

where $d$ is the focal spot diameter in $\mathrm{mm}, f$ is the frequency in $\mathrm{MHz}, D$ is the element diameter in $\mathrm{mm}, l$ is the focal length in $\mathrm{mm}$, and $c$ is the speed of sound in $\mathrm{m} / \mathrm{s}$.

Based on the examined relation, the new focal spot diameter in phenolic is larger than $0.6 \mathrm{~mm}$ which is statistically a big shift from the original value of around $0.3 \mathrm{~mm}$ in other materials.

Nevertheless, the expected stresses were still obtainable using the measured contact area. Generally, the results of the experimental stresses measured from the contact of phenolic and steel sphere are always lower than the Hertz stresses, except for load $100 \mathrm{~N}$. This observation signifies the occurrence of plastic deformation in the material. The same behavior was not observed for the contact of phenolic and glass spheres. The reason for this was due to the limited contact size with loading because of crack formations on the surface of the sphere. 
Table 5 Contact stresses

\begin{tabular}{llllll}
\hline Contact & Load $(N)$ & $\sigma_{\text {Exp }}(\mathrm{MPa})$ & $R$ Coefficient & $\sigma_{\text {Ref }}(\mathrm{MPa})$ & $\sigma_{\mathrm{Hz}}(\mathrm{MPa})$ \\
\hline Polycarbonate and Steel Sphere & 100 & 127 & -0.493 & 122 & 80 \\
& 200 & 113 & -0.47 & 105 & 101 \\
& 300 & 106 & -0.477 & 110 & 115 \\
& 400 & 105 & -0.481 & 114 & 127 \\
Polycarbonate and Glass Sphere & 100 & 75 & -0.4 & 26 & 80 \\
& 200 & 88 & -0.47 & 42 & 101 \\
& 300 & 86.5 & -0.52 & 71 & 115 \\
Phenolic and Steel Sphere & 400 & 88.5 & -0.525 & 74 & 127 \\
& 100 & 260 & 0.75 & 5 & 110 \\
& 200 & 113 & 0.63 & 10 & 138 \\
Phenolic and Glass Sphere & 300 & 118 & 0.64 & 9 & 158 \\
& 400 & 127 & 0.63 & 10 & 174 \\
& 100 & 105 & 0.53 & 6.5 & 110 \\
& 200 & 177 & 0.53 & 6.5 & 138 \\
& 300 & 226 & 0.52 & 7 & 158 \\
& 400 & 199 & 0.54 & 6 & 174 \\
\hline
\end{tabular}

\subsection{Numerical Model}

Vertical displacement occurs at locations where the reflected coefficient is different from unity. The amount displaced depends on the reflection coefficient value and the material properties. By comparing the displacements obtained from the numerical model for the contact of a cylinder at distinct locations to the reflection coefficients obtained from the experiments, a relation between both terms was obtained. Generally, the experimentally scanned materials showed a similar pattern for the reflection coefficient where it reaches its minimum value inside the contacting area as seen in Figs. 5 and 6. Notably, the reflection coefficient increases toward the outer boundaries. All the patterns appear to have a circular shape at the center, being the same as the center of the contact circle. Few contours did not have a perfectly circular pattern; instead, they appear to undergo more displacements on one side than another at higher loads. Some experiments showed more like an elliptical contact, whereas others especially showed some irregularities.

Since polycarbonate is dominated by elastic deformation, some bending at the less supported side may occur at high loads. Describing the reflection coefficient shows that phenolic-steel is around 0.825; this is because high reflected waves in air and steel interface are around 0.85 . Thus, it was not possible to distinguish the ones reflected from the air and those from steel by using the negative sign to phase shifts due to the large attenuations that were observed for phenolic operations. The negative sign, however, was observed in polycarbonates as lower attenuations were found. This justifies the reasons that more data could be observed from the polycarbonate-steel interaction than from the phenolic-steel interaction. Also, this can be seen from the $R_{\text {critical value }}$ for both cases, where the value in polycarbonate is lower and hence allows examining the reflection coefficients at the outer contact boundary. On the other side, at low loads, the phenolic-steel cylinder interaction shows a small contact size for the zone located inside the $R$ coefficient interval of 0.8 . This would initially suggest that the critical reflection coefficient of the contact is more significant than 0.8 (around 0.9). However, at higher loads, it becomes clear that the contact boundary has a critical $R$ of around 0.825 . This suggests that initially, we were not able to obtain a perfect contact as the load was low. Also, the similarity between phenolic-air and phenolic-steel interfaces in terms of high reflection coefficients makes it harder to differentiate the difference at low loads. For this specific case (contact between phenolic and steel cylinder) the reflection coefficient values between 0.9 and 1 are shown in Fig. 6a, unlike the other scenarios. This is done to show the development of the stressed region around the contact, suggesting that vertical displacements have occurred. For phenolic-glass, the reflection coefficient is around 0.65 (Lower number of reflected waves in the glass interface, around 0.55 from Eq. 2). Negative signs were not observed in this method due to the same reasons discussed above. However, the results were more precise and more detailed than using steel spheres because it is easier to distinguish the reflection coefficients of the phenolic-air interface (no contact) from that of the phenolic-glass interface (contact region).

The Hertzian stresses show a slightly lower correlation with the experimental stresses at the higher loads $300 \mathrm{~N}$ and $400 \mathrm{~N}$. This is because of slight plastic deformations in the material. Other slight differences in the results could 
Fig. 5 Experimental scanned contact at different loads for: a polycarbonate with steel cylinder and $\mathbf{b}$ polycarbonate with glass cylinder
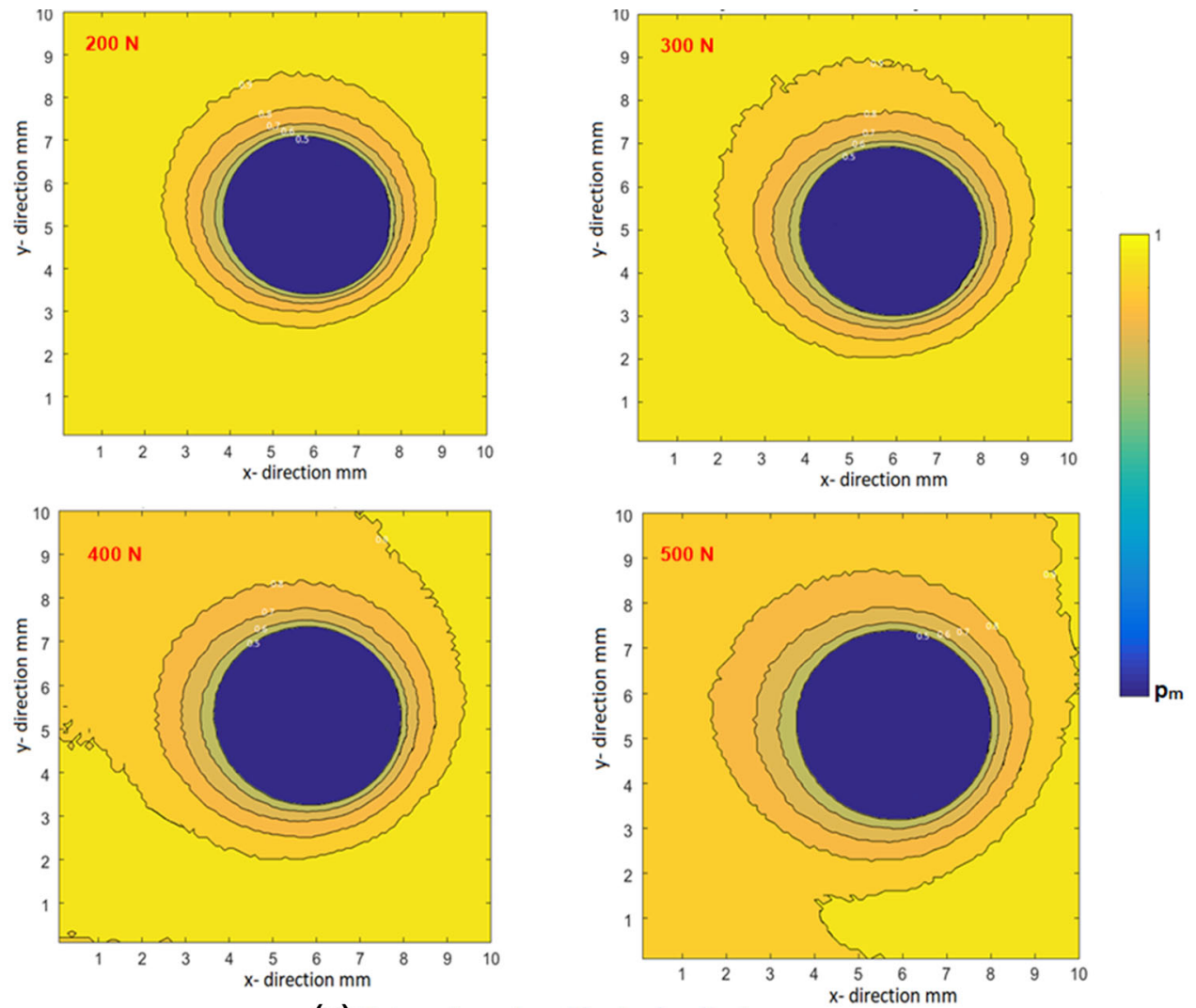

(a) Polycarbonate with steel cylinder
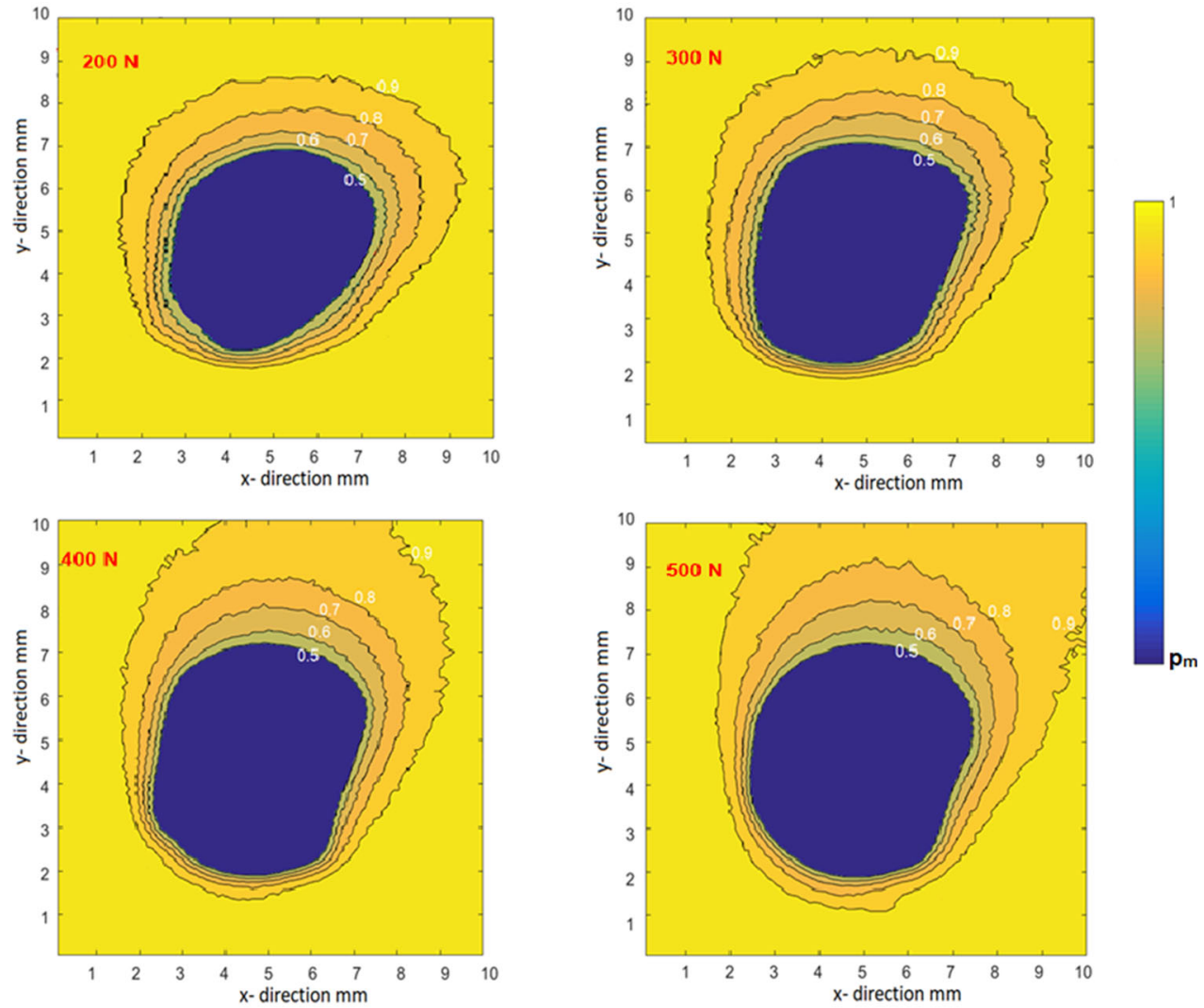

(b) Polycarbonate with glass cylinder 

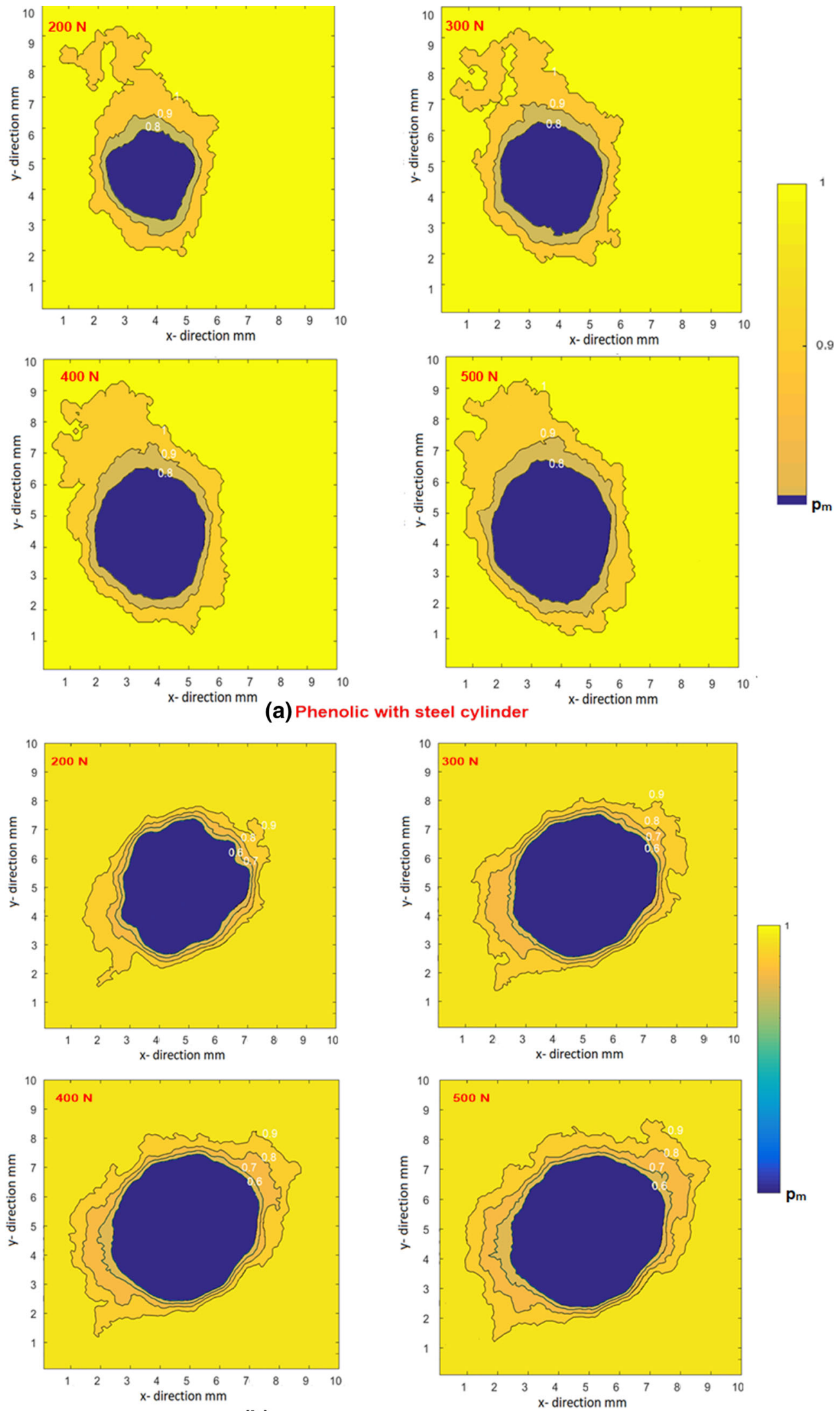

(b) Phenolic with glass cylinder

Fig. 6 Experimental scanned contact at different loads for: a phenolic with steel cylinder and $\mathbf{b}$ phenolic with glass cylinder 
be attributed to some inaccuracy in measuring the contact zone, especially at low loads where the standard deviation is around $\pm 0.1 \mathrm{~mm}$. Nevertheless, these results are confirming that the primary deformation in the polycarbonate is elastic.

The experimental results of phenolic stresses have wide variations. The stress measured from the reflection coefficient appears to be much lower than that calculated from the contact area and Hertz law. This is because the reflection coefficient did not show significant changes under the tested load conditions. Generally, the results of the experimental stresses measured from the contact of phenolic and steel sphere are always lower than the Hertz stresses, except for load $100 \mathrm{~N}$. This observation signifies the occurrence of plastic deformation in the material.

Figures 7 and 8 show the experimentally scanned images of the contact problem for the plate materials with steel and glass spheres. This contact is now much smaller than those observed in Figs. 5 and 6. On the other hand, the contact's vertical displacements seem to cover a greater distance for a given loading condition. This is because the contact stresses in spheres at a given load are much higher than those in cylinders as a result of a smaller contact area. Following the critical reflection coefficient for each scenario, the contact diameter was obtained as previously shown in Table 4. In most of the experiments, the contact showed a circular pattern except few cases where an elliptical pattern was observed. However, at higher loads, all patterns shift toward a perfect circular shape.

Another important observation from Figs. 7 and 8 is the extent of vertical displacements surrounding the contact zone. This can be seen from the reflection coefficient values that are less than a value of 1 . In all the tested scenarios, polycarbonate showed a greater extent (over twice) than that of phenolic e.g., compare Figs. $7 \mathrm{a}$ and $8 \mathrm{a}$ for all loading conditions. These displacements also show a circular to an elliptical-shaped pattern in most of the experiments. Many factors could affect this shape such as the boundary conditions for the fixed plate and possible manufacturing deformities in the materials. For a perfect elastic contact, the vertical displacements should follow a circular pattern based on Hertz law. Polycarbonate material appears to follow the Hertz law for circular patterns more than phenolic does and this suggests some plastic deformations in the latter case. This conforms with the ratio $E / Y$ which suggests that more plastic deformation occur as this parameter increases.

\subsection{Outlook}

Relating the study findings to hydraulic fracturing reveals that the contact of proppant and rocks is not identically following the Hertz law. This appeared from observing the similarity of contact stresses of the tested materials instead of having a larger variation than that of Hertzian stresses. This confirms that part of the contact energy in phenolic material was dissipated in the plastic deformation. Neglecting the actual value of Young's modulus, the study confirms that the material with a larger elastic modulus to yield strength ratio $(E / Y)$ is more susceptible to proppant embedment, leading to a loss in fracture conductivity. However, the degree of proppant embedment/displacement depends on the stress-strain properties of the rock, specifically on the elastic modulus and plastic deformation behavior. This is the reason the contact of polycarbonate plate, which has a lower Young's modulus, showed a larger contact size than that of phenolic for all scenarios considered. Similar observations were noted by several studies [9, 32, 33]. Therefore, for a fixed Young's modulus, the material with a higher $E / Y$ ratio will be susceptible to plastic deformations, increasing the proppant embedment in a rock-proppant interaction. However, a lower $E / Y$ ratio will result in higher contact stresses in a rockproppant interaction that might result in either rock and/or proppant crushing. This outcome becomes substantial with rough surfaces due to the uneven load distribution during contact. Both proppant embedment and proppant/rock crushing are not favorable during hydraulic fracturing as they can reduce the fracture conductivity and limit well productivity.

The novelty of this study is that it is the first to assess the physics and contact mechanics theories of proppant-rock interaction. Although the current study only considers the contact of a single sphere with a flat plate, future studies can consider multiple spheres inside the experimental cell. With more advancements in ultrasonic technology, it might be possible to replicate the idea of a conductivity cell using the experimental cell used in this study, where smaller-sized proppants can then be used and the distribution of contact stresses, contact areas, and proppant embedment can be measured.

\section{Conclusion}

This paper aims to provide insight into the nature of contact between proppant and brittle shale rocks. The current study adopted a combined method to understand the mechanical properties' effect on the deformation behavior of rocks at increasing loads. This was conducted using manufactured materials instead of actual proppants and rocks. All materials were selected based on Young's modulus and Yield strength. The findings are encapsulated as follows:

1- During the usage of the ultrasound, the transducers focal spot diameter successfully obtained and collected signals from the inner and outer contact zone.

2- Critical reflection coefficients are $0.62,0.85,0.55$, and 0.54 for the contact of phenolic-glass, phenolic-steel, 
Fig. 7 Experimental scanned contact at different loads for: a polycarbonate with steel sphere and $\mathbf{b}$ polycarbonate with glass sphere
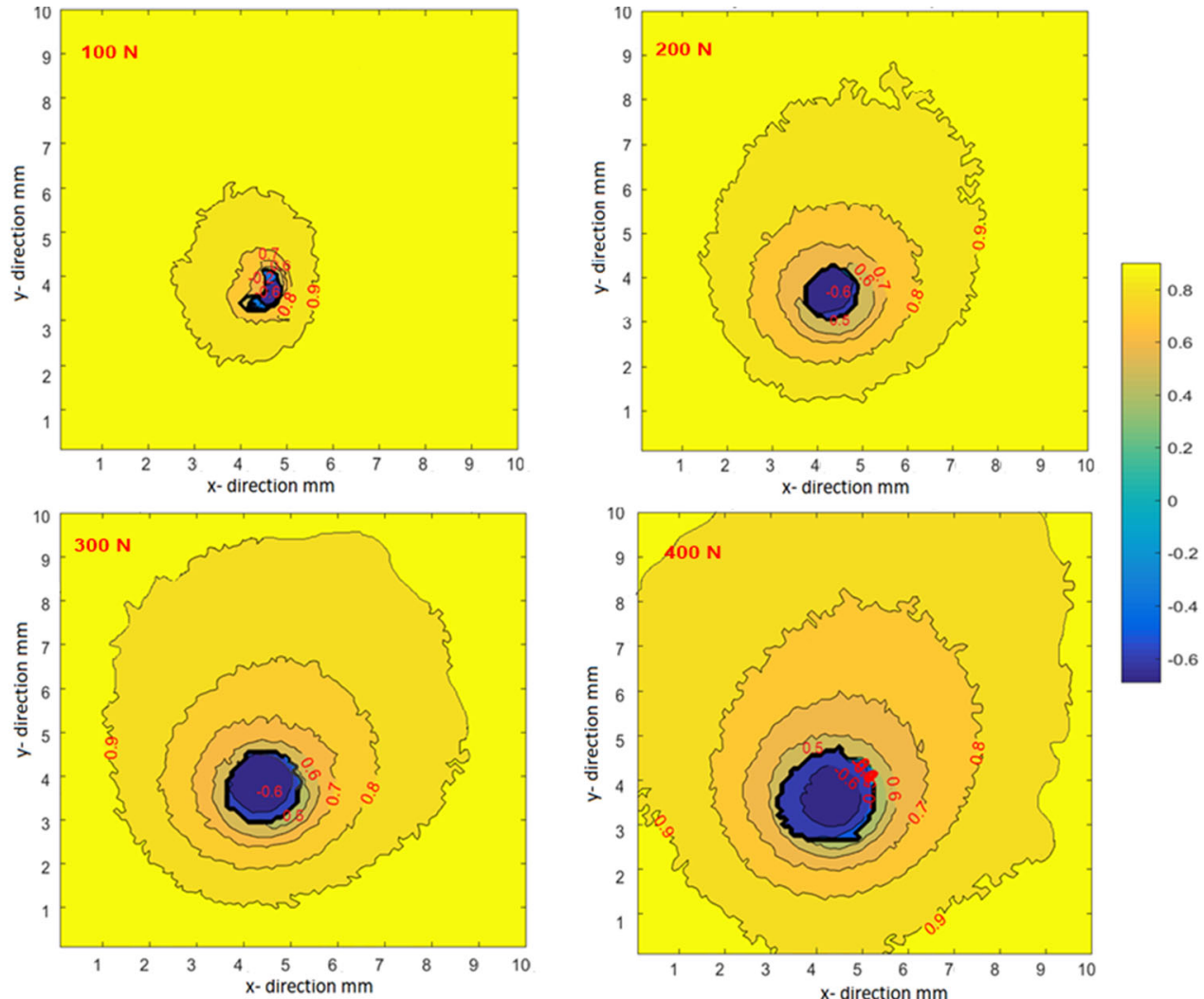

(a) Polycarbonate with steel sphere
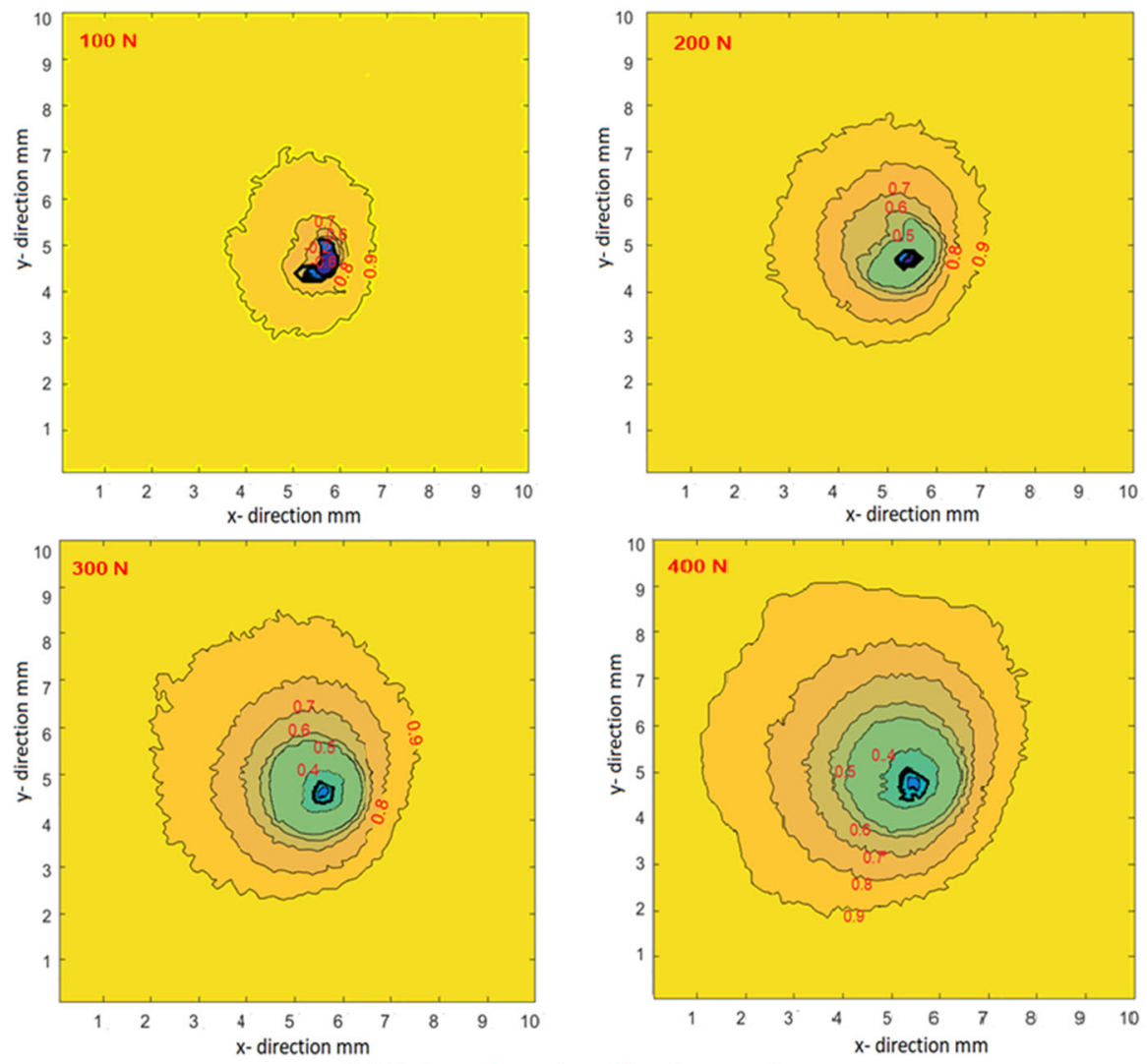

(b) Polycarbonate with glass sphere

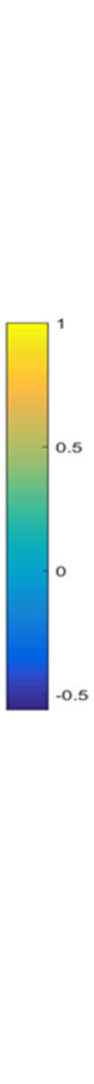


Fig. 8 Experimental scanned contact at different loads for: a phenolic with steel sphere and b phenolic with glass sphere
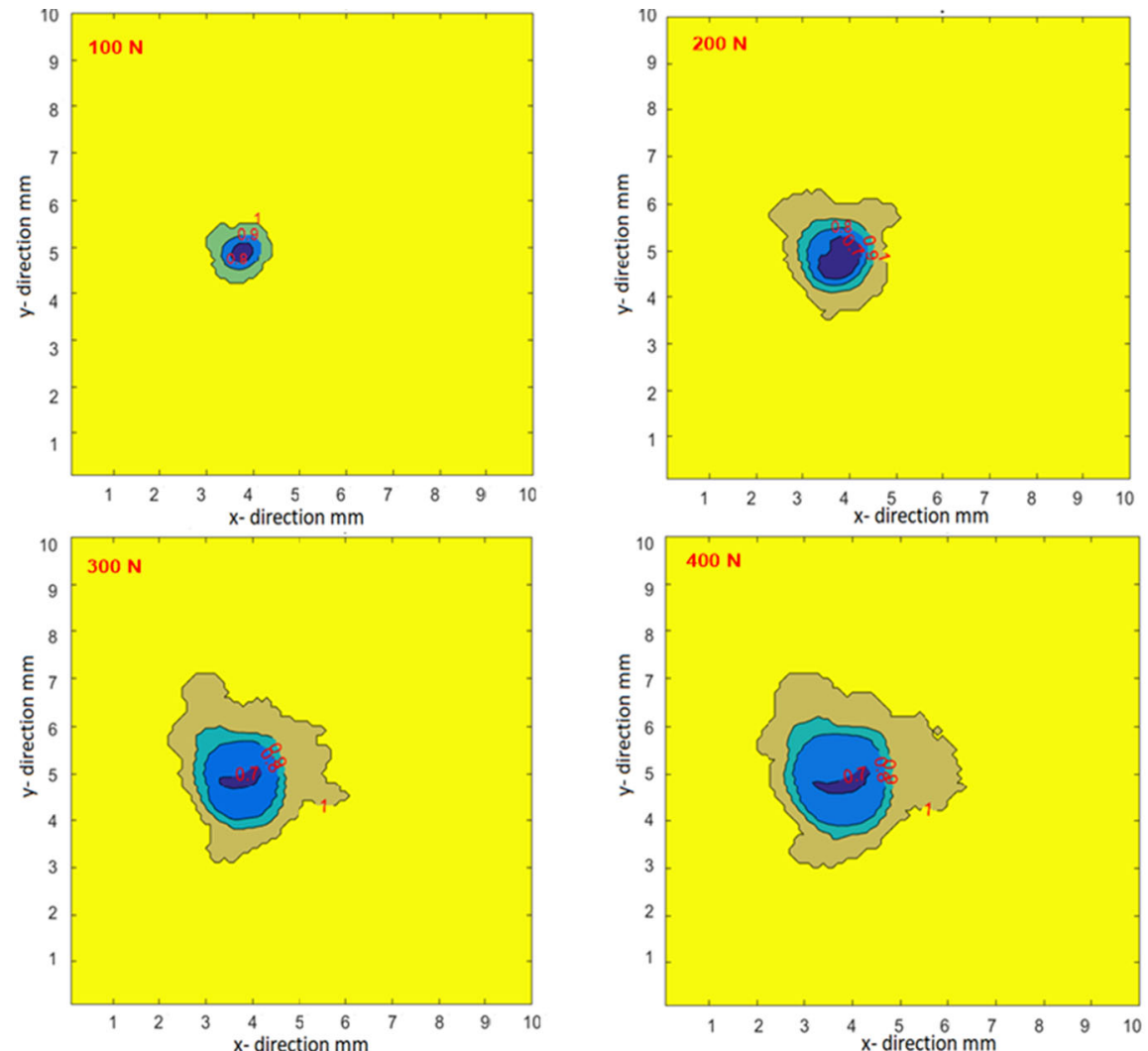

(a) Phenolic with steel sphere
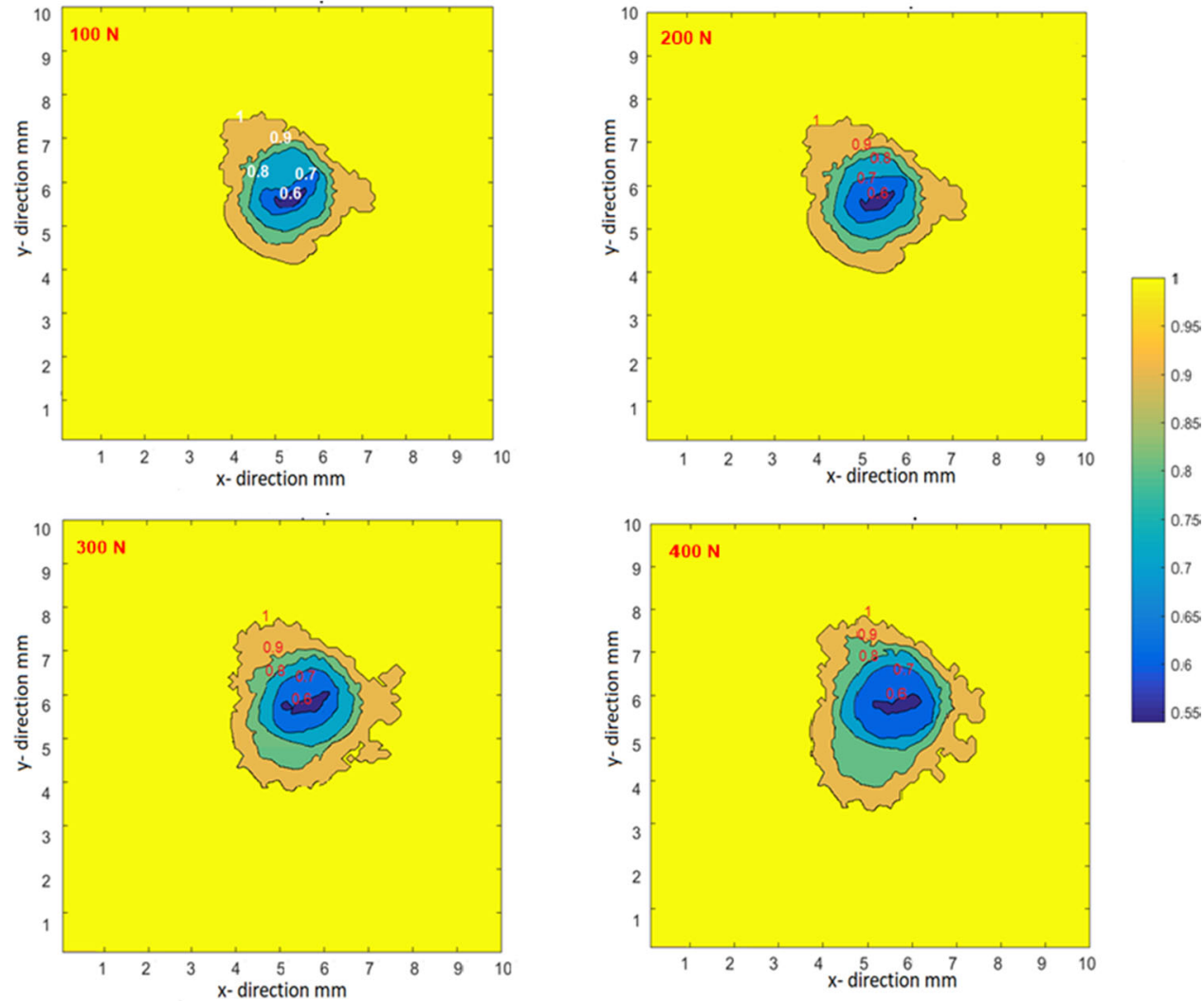

(b) Phenolic with glass sphere 
polycarbonate-glass, and polycarbonate-steel, respectively.

3- The calibration test results indicated that the relations between the stresses and reflection coefficients strictly followed the power-law equation-even at higher stresses. This was confirmed by $R^{2}$ ranged between (0.98 to 0.99 ).

4- For contact determination, Hertz elastic theory was applied for the phenolic and polycarbonate plates, and it showed some variations to what has been obtained experimentally. This is evidently caused by the plastic deformation that took place at the phenolic surfaces.

5- The difference in the polycarbonate stresses for steel spheres, obtained using stress-reflection coefficient, and their corresponding Hertz are insignificant. However, phenolic stresses difference is substantial for both high and low loads, which is explained by the high attenuation coefficient of phenolic that limited the quality of the reflected signal.

6- Most of the scanned materials showed a circular pattern in the outer contact boundary-the reflection coefficient increases toward the outer boundaries. Only a few contours deviated and appeared to undergo more displacements toward one side (elliptical) at higher loads.

7- The extent of vertical displacements along the $x-y$ planes is greater for the polycarbonate material due to the lower $E / Y$. On the other hand, the phenolic material was limited to smaller areas due to the plastic deformations at higher loads.

8- The study outcomes confirmed that part of the contact energy in phenolic material was dissipated in the plastic deformation. This is due to the lower yield strength for this material compared to polycarbonate.

9- The extent of vertical displacements surrounding the contact zone is greater for the polycarbonate materials due to lower $E / Y$, while the phenolic material was limited to smaller areas not exceeding $50 \%$ of polycarbonate for all tested load conditions.

10- For a fixed Young's modulus, the material having a higher $E / Y$ ratio will be susceptible to plastic deformations at lower stress resulting in proppant embedment.

11- For a fixed Young's modulus, the material having a lower $E / Y$ ratio will be susceptible to higher contact stresses that might result in either rock and/or proppant crushing.

Acknowledgements The authors acknowledge the support provided by the University of Aberdeen in completing this work.

Open Access This article is licensed under a Creative Commons Attribution 4.0 International License, which permits use, sharing, adaptation, distribution and reproduction in any medium or format, as long as you give appropriate credit to the original author(s) and the source, provide a link to the Creative Commons licence, and indi- cate if changes were made. The images or other third party material in this article are included in the article's Creative Commons licence, unless indicated otherwise in a credit line to the material. If material is not included in the article's Creative Commons licence and your intended use is not permitted by statutory regulation or exceeds the permitted use, you will need to obtain permission directly from the copyright holder. To view a copy of this licence, visit http://creativecomm ons.org/licenses/by/4.0/.

\section{References}

1. Gharibi, A.; Zoveidavianpoor, M.: Hydraulic fracturing for improved oil recovery. J. Adv. Res. Fluid Mech. Therm. Sci. 9(1), $1-18(2015)$

2. Zoveidavianpoor, M.; Gharibi, A.; Bin Jaafar, M.Z.: Experimental characterization of a new high-strength ultra-lightweight composite proppant derived from renewable resources. J. Pet. Sci. Eng. (2018). https://doi.org/10.1016/j.petrol.2018.06.030

3. Alramahi, B.; Sundberg, M.I.: Proppant embedment and conductivity of hydraulic fractures in shales. In: 46th US Rock Mechanics/Geomechanics Symposium 2012, 2012

4. Terracina, J.M.; Turner, J.M.; Collins, D.H.; Spillars, S.E.: Proppant selection and its effect on the results of fracturing treatments performed in shale formations. Proc. SPE Ann. Techn. Conf. Exhib. (2010). https://doi.org/10.2118/135502-ms

5. Johnson, K.L.: Mechanics of elastic contacts. Tribol. Int. (1994). https://doi.org/10.1016/0301-679x(94)90066-3

6. Greenwood, J.A.; Tripp, J.H.: Contact of two nominally flat rough surfaces. Proceedings of the institution of mechanical engineers 185(1), 625-633 (1970). https://doi.org/10.1243/pime_proc_ 1970_185_069_02

7. Hisakado, T.: Effect of surface roughness on contact between solid surfaces. Wear (1974). https://doi.org/10.1016/00431648(74)90163-X

8. Adams, G.G.; Nosonovsky, M.: Contact modeling - forces. Tribol. Int. (2000). https://doi.org/10.1016/S0301-679X(00)00063-3

9. Ghaednia, H.; Wang, X.; Saha, S.; Xu, Y.; Sharma, A.; Jackson, R.L.: A review of elastic-plastic contact mechanics. Appl. Mech. Rev. (2017). https://doi.org/10.1115/1.4038187

10. Zhou, C.; Huang, F.; Han, X.; Gu, Y.: An elastic-plastic asperity contact model and its application for micro-contact analysis of gear tooth profiles. Int. J. Mech. Mater. Des. (2017). https://doi.org/10. 1007/s10999-016-9338-1

11. Aymerich, F.; Pau, M.: Assessment of nominal contact area parameters by means of ultrasonic waves. J. Tribol. (2004). https://doi. org/10.1115/1.1760764

12. Marshall, M.B.; Lewis, R.; Dwyer-Joyce, R.S.; Olofsson, U.; Björklund, S.: Experimental characterization of wheel-rail contact patch evolution. J. Tribol. (2006). https://doi.org/10.1115/1. 2197523

13. Wang, S.; Yao, X.F.; Yang, H.; Huang, S.H.: Measurement and evaluation on contact stress at the rubber contact interface. Meas. J. Int. Meas. Confed. (2019). https://doi.org/10.1016/j.measurement. 2019.07.018

14. Mishra, R.; Burela, R.G.; Pathak, H.: Crack interaction study in piezoelectric materials under thermo-electro-mechanical loading environment. Int. J. Mech. Mater. Des. (2019). https://doi.org/10. 1007/s10999-018-9410-0

15. Zou, J.; Luo, Y.; Yu, X.; Li, J.; Xi, Y.; Zhang, L.; Guo, W.; Lin, G.: Extraction of indium from by-products of zinc metallurgy by ultrasonic waves. Arab. J. Sci. Eng. (2020). https://doi.org/10.1007/ s13369-020-04471-0

16. León Ramírez, J.A.; Juan, L.M.; Carrillo, J.: material damage evolution for plain and steel-fiber-reinforced concrete under uncon- 
fined compression loading by dynamic ultrasonic tests. Arab. J. Sci. Eng. (2018). https://doi.org/10.1007/s13369-018-3301-4

17. Drinkwater, B.W.; Dwyer-Joyce, R.S.; Cawley, P.: A study of the interaction between ultrasound and a partially contacting solidsolid interface. Proc. R. Soc. A Math. Phys. Eng. Sci. 452, 1996 (1955). https://doi.org/10.1098/rspa.1996.0139

18. Pau, M.; Aymerich, F.; Ginesu, F.: Ultrasonic measurements of nominal contact area and contact pressure in a wheel-rail system. Proc. Inst. Mech. Eng. Part F J. Rail Rapid Transit (2000). https:// doi.org/10.1243/0954409001531333

19. Pesaresi, L.; Fantetti, A.; Cegla, F.; Salles, L.; Schwingshackl, C.W.: On the use of ultrasound waves to monitor the local dynamics of friction joints. Exp. Mech. (2020). https://doi.org/10.1007/ s11340-019-00550-y

20. Brunskill, H.; Hunter, A.; Zhou, L.; Dwyer Joyce, R.; Lewis, R.: An evaluation of ultrasonic arrays for the static and dynamic measurement of wheel-rail contact pressure and area. Proc. Inst. Mech. Eng. Part J J. Eng. Tribol. (2020). https://doi.org/10.1177/ 1350650120919889

21. Johnson, K.L.: The correlation of indentation experiments. J. Mech. Phys. Solids (1970). https://doi.org/10.1016/0022-5096(70)900293

22. Kogut, L.; Komvopoulos, K.: Analysis of the spherical indentation cycle for elastic-perfectly plastic solids. J. Mater. Res. (2004). https://doi.org/10.1557/JMR.2004.0468

23. Li, Q.; Chen, M.; Jin, Y.; Zhou, Y.; Wang, F.P..; Zhang, R.: Rock mechanical properties of shale gas reservoir and their influences on hydraulic fracture. In: Society of Petroleum Engineers - International Petroleum Technology Conference 2013, IPTC 2013: Challenging Technology and Economic Limits to Meet the Global Energy Demand (2013) https://doi.org/10.2523/iptc-16580-ms

24. Bou-Hamdan, K.F.: Design and implementation of an ultrasonic scanner setup that is controlled using MATLAB and a microcontroller. Adv. Sci. Technol. Eng. Syst. J (2021). https://doi.org/10. 25046/aj060211
25. Bou-Hamdan, K.: An experimental approach that scans the surface area using ultrasonic waves to generate a two-dimensional image. In: 20207 th International Conference on Electrical and Electronics Engineering (ICEEE), pp. 264-267 (2020) https://doi.org/10.1109/ ICEEE49618.2020.9102557

26. Hodgson, K.; Dwyer-Joyce, R.S.; Drinkwater, B.W.: Ultrasound as an experimental tool for investigating engineering contacts. Tribologia 19(4), 9-17 (2000)

27. Quinn, A.M.; Drinkwater, B.W.; Dwyer-Joyce, R.S.: The measurement of contact pressure in machine elements using ultrasound. Ultrasonics (2002). https://doi.org/10.1016/S0041624X(01)00089-0

28. Dehoux, T.; Wright, O.B.; Voti, R.L.: Picosecond time scale imaging of mechanical contacts. Ultrasonics (2010). https://doi.org/10. 1016/j.ultras.2009.08.008

29. Zhou, L.; Brunskill, H.; Pletz, M.; Daves, W.; Scheriau, S.; Lewis, R.: Real-time measurement of dynamic wheel-rail contacts using ultrasonic reflectometry. J. Tribol. (2019). https://doi.org/10.1115/ 1.4043281

30. Krautkrämer, J.; Krautkrämer, H.: Ultrasonic testing of materials. (1990) https://doi.org/10.1007/978-3-662-10680-8

31. Liddell, M.R.; Deng, G.; Hauck, W.W.; Brown, W.E.; Wahab, S.Z.; Manning, R.G.: Evaluation of glass dissolution vessel dimensions and irregularities. Dissolut. Technol. (2007). https://doi.org/ 10.14227/DT140107P28

32. Chen, M.; Zhang, S.; Liu, M.; Ma, X.; Zou, Y.; Zhou, T.; Li, N.; Li, S.: Calculation method of proppant embedment depth in hydraulic fracturing. Pet. Explor. Dev. (2018). https://doi.org/10. 1016/S1876-3804(18)30016-8

33. Zhi, S.; Elsworth, D.: Proppant embedment in coal and shale: Impacts of stress hardening and sorption. Int. J. Coal Geol. (2020). https://doi.org/10.1016/j.coal.2020.103545 